\title{
Genome-Wide Linkage Scan for Prostate Cancer Susceptibility From the University of Michigan Prostate Cancer Genetics Project: Suggestive Evidence for Linkage at16q23
}

\author{
Ethan M. Lange ${ }^{1,2,3}$, Jennifer L. Beebe-Dimmer ${ }^{4,5}$, Anna M. Ray ${ }^{6}$, Kimberly A. Zuhlke $^{6}$, \\ Jaclyn Ellis ${ }^{3}$, Yunfei Wang ${ }^{1}$, Sarah Walters ${ }^{6}$, and Kathleen A. Cooney $6,7,{ }^{,}$ \\ ${ }^{1}$ Department of Genetics, University of North Carolina, Chapel Hill, North Carolina \\ ${ }^{2}$ Department of Biostatistics, University of North Carolina, Chapel Hill, North Carolina \\ ${ }^{3}$ The Curriculumin Genetics and Molecular Biology, University of North Carolina, Chapel Hill, North \\ Carolina \\ ${ }^{4}$ Karmanos Cancer Institute, Detroit, Michigan \\ ${ }^{5}$ Department of Internal Medicine, Wayne State University, Detroit, Michigan \\ ${ }^{6}$ Department of Internal Medicine, University of Michigan Medical School, Ann Arbor, Michigan \\ ${ }^{7}$ Department of Internal Medicine and Urology, University of Michigan Medical School, Ann Arbor, \\ Michigan
}

\section{Abstract}

BACKGROUND—Prostate cancer linkage studies have been used to localize rare and presumably highly penetrant cancer susceptibility genes. Underlying genetic heterogeneity, as well as the high sporadic background of the disease, has resulted in many signals that are often not reproducible between research studies.

METHODS-We conducted a SNP-based genome wide linkage scan on 131 Caucasian prostate cancer families participating in the University of Michigan Prostate Cancer Genetics Project (PCGP).

RESULTS-The strongest evidence for linkage was detected at 16q23 (LOD $=2.70$ at rs1079635). Prostate cancer linkage to the same region of $16 \mathrm{q} 23$ has been observed by others and the region contains several strong candidate genes including the known prostate cancer tumor suppressor genes $A T B F 1$ and WWOX. This linkage signal was not detected in our prior linkage study on 175 PCGP families, illustrating the genetic heterogeneity underlying prostate cancer susceptibility.

CONCLUSIONS-Further linkage studies in combination with tumor analyses from linked families are in progress to identify the putative hereditary prostate cancer gene at 16q23.

\section{Keywords}

familial; gene; epidemiology; aggressive disease 


\section{INTRODUCTION}

Prostate cancer is the most common cancer diagnosed among American men and the second leading cause of cancer deaths with an estimated 186,320 new cases and 28,660 deaths expected in the United States in 2008 [1]. The significance of a heritable component in prostate cancer is undeniable as evidenced by findings from segregation analyses, genome-wide linkage and association scans, as well as twin and other family-based epidemiologic studies [2]. However, the localization of highly penetrant prostate cancer susceptibility genes has proven to be extremely difficult. Prostate cancer is a clinically heterogeneous disease with complex genetic underpinnings. The majority of the genetic variants that are consistently associated with an increased risk of prostate cancer to this point are not highly penetrant and are relatively common (>5\%) across populations [3]. Genome-wide prostate cancer association studies are specifically powered to detect common, low-penetrant variants associated with the disease, but are not designed to detect rare, highly penetrant disease causing mutations. Whole genome-wide linkage studies of families with multiple affected relatives have been successful for identifying genes containing mutations that are associated with enhanced susceptibility to cancers of the breast, ovary, colorectum, endometrium and skin (melanoma), but not prostate, likely due in part to the large number of pre-clinical cancers detected as a result of PSA screening. Despite the challenges, a large collaborative linkage study on 1,233 prostate cancer families conducted by the International Consortium on Prostate Cancer Genetics (ICPCG) [4] has identified several chromosomal regions of interest based on suggestive evidence of linkage (LOD scores $>1.86$ ) including 5q12, 8p21, 15q11,17q21, and 22q12. The aim of the current investigation is to provide further clues in the search for prostate cancer susceptibility genes by conducting a genome-wide linkage scan on new families recruited into an established study of early-onset and/or hereditary prostate cancer.

\section{MATERIALS AND METHODS}

Since its inception in 1995, the goal of the Prostate Cancer Genetics Project (PCGP) has been to identify genes predisposing to inherited forms of prostate cancer. Enrollment into the PCGP is restricted to (1) men diagnosed with prostate cancer with at least one living first-or seconddegree relative also diagnosed with prostate cancer or (2)men diagnosed with prostate cancer at $\leq 55$ years of age without a family history of the disease. Eligibility criteria for inclusion in PCGP linkage studies are more stringent and include (1) at least three related family members with prostate cancer (or two cases with an average age at diagnosis $\leq 56$ years) and (2) DNA available on at least two cases that are informative for linkage analysis. Prostate cancer diagnoses are confirmed by medical record whenever possible. Otherwise, independent confirmation of the diagnosis by at least two family members is required. All subjects provide written informed consent to participate in the study and for release of pertinent medical records. The protocol and consent documents were approved by the University of Michigan Medical School Institutional Review Board. DNA samples were collected and genotyped from 471 individuals from 131 families, including 352 diagnosed cases. The current investigation is limited to Caucasian families due to the small number of African American families $(n=6)$ collected and the marked differences in allele frequencies and linkage disequilibrium patterns between African American and Caucasians.

Clinical data abstracted from medical records was used to classify prostate cancer into either aggressive or non-aggressive forms. The definition of clinically aggressive disease in this study was identical to the definition used in our previous genome-wide scan of aggressive disease [5], and similar to the definitions used by other investigative teams participating in the ICPCG [6]. Specifically, affected men were considered to have aggressive disease if they met at least one of the following criteria: (1) regional or distant stage based on pathology if radical prostatectomy was done, otherwise clinical stage [American Joint Commission on Cancer 
(AJCC) stage III (T3, N0, M0) or stage IV (T4, N0, M0) or any T, N1, M0 or any T, N0, M1]; (2) Gleason grade at diagnosis of $\geq 7$ (or poorly differentiated grade if no Gleason score was available); (3) pre-diagnostic PSA $\geq 20 \mathrm{ng} / \mathrm{ml}$; or (4) prostate cancer listed as the primary cause of death on a death certificate. Men without any of these criteria were coded as unknown for the linkage analyse of aggressive disease.

Genomic DNA was prepared from blood samples using standard techniques. DNA samples were sent to the Center for Inherited Disease Research (CIDR) for genotyping. CIDR performs SNP genome scan linkage genotyping using Illumina's Human Linkage-12 Marker Panel. This panel includes 5,871 SNP loci spread across the genome at an average marker density of 0.43 cM coverage among Caucasians.

\section{Statistical Methods}

Genome-wide multipoint nonparametric linkage analyses were performed over a $1 \mathrm{cM}$ grid using the computer software package Merlin [7]. The "Pairs" score statistic [8] was used to identify chromosomal regions with excess identity-by-descent allele sharing among affected relatives. Equal weights were assumed for all pedigrees; the exponential model [9] was used to convert nonparametric linkage (NPL) Z-scores to LOD scores. Allele frequencies were estimated using all available data from all 131 Caucasian PCGP families included in this study and inter-marker distances and order were provided by CIDR. Merlin's "-rsq 0.1" command was used to cluster together markers in linkage disequilibrium to avoid the upward bias in LOD scores caused by including markers with non-independent genotypes in the pedigree founders.

Linkage analyses were performed separately for all 131 Caucasian PCGP families and for a subset of 57 informative families that had two or more related cases of aggressive prostate cancer. For the aggressive disease linkage analyses, men with non-aggressive prostate cancer had their phenotype recoded as "unknown." Pedigrees were included in this analysis if there were at least two genetically related men with aggressive disease and if they were informative for linkage.

\section{RESULTS}

Of the 131 PCGP families included in the current genome scan, the average age of diagnosis among prostate cancer cases was 61.9 years with $72 \%$ of families having an average age of diagnosis among confirmed cases of $\leq 65$ years. Fifty-four percent of cases were characterized as having aggressive disease and 57 (43.5\%) families had two or more cases classified as aggressive. The average number of affected men per family was 3.8 and 59 families (44\%) had four or more relatives with prostate cancer. A comparison of the characteristics of families in the current analysis with the 175 PCGP families included in our first genome scan is presented in Table I.

Although no significant evidence of linkage was detected in the genome-wide linkage analysis, two regions (chromosomes $1 \mathrm{p}[\mathrm{LOD}=1.89]$ and $16 \mathrm{q}[\mathrm{LOD}=2.70]$ ) were detected to have suggestive evidence for linkage based on Lander and Kruglyak's [10] definition (LOD>1.86) (Fig. 1). Modest positive LOD scores were observed at the five chromosomal regions with suggestive linkage identified by the ICPCG [1,4]: 5q12 (LOD = 0.18), 8p21 (LOD = 0.52), $15 \mathrm{q} 11(\mathrm{LOD}=0.35), 17 \mathrm{q} 21(\mathrm{LOD}=0.28)$, and 22q12 (LOD $=0.28)$. Weak evidence for linkage was also found in regions identified by genetic association studies, namely 8q24 (LOD $=0.59)$ and $17 \mathrm{q} 12(\mathrm{LOD}=0.23)$, but no evidence was found at $17 \mathrm{q} 24(\mathrm{LOD}=0.00)$. The maximum LOD score observed for each chromosome is presented in Table II.

From the 131 PCGP families, 57 families had multiple cases of aggressive prostate cancer and were informative for nonparametric linkage analysis. Two regions had suggestive evidence for 
linkage to aggressive prostate cancer (chromosomes 9q [LOD $=2.96]$ and $10 \mathrm{q}[\mathrm{LOD}=1.96]$ ) (Fig. 1 and Table II).No evidence for linkage (LOD $=0.00$ ) was detected at $6 \mathrm{p} 22$, the region with the strongest suggestive linkage in the study of aggressive prostate cancer by the ICPCG [6].

\section{DISCUSSION}

In this genome wide scan of the 131 families recruited most recently into the Prostate Cancer Genetics Project, the evidence for prostate cancer linkage was strongest at 16q23 (LOD = 2.70; near rs 1079635). Furthermore, in a subset of 57 pedigrees with two or more cases of aggressive prostate cancer, strongly suggestive evidence for aggressive prostate cancer linkage was observed at 9q33 ( $\mathrm{LOD}=2.96$; near rs 1405). LOD scores of greater than one were also observed on chromosomes 1, 2, 3, 4, 7, 8, 10,14, and 15 either on all pedigrees and/or the subset of families with aggressive prostate cancer.

Our linkage signal on chromosome 16q is illustrated in more detail in Figure 2. The marker nearest the peak is rs1079635 which is in an intron of the WWOX (WW domain-containing oxidoreductase) gene which maps to 16q23.3-q24.1. The 1-LOD support interval is approximately 7.4 megabases; it contains 30 known genes in addition to WWOX as well as a number of unknown transcripts.

Prior linkage studies have demonstrated evidence for prostate cancer linkage at 16q23 [1113]. In a genome-wide scan of 504 brothers with prostate cancer from 230 families, Suarez et al. [11] reported evidence for linkage on a $\sim 16.8 \mathrm{cM}$ region on $16 \mathrm{q} 23$ (multipoint $Z$-scor $=3.15$ for marker D16S3096). Note that D16S3096 is approximately $1 \mathrm{Mb}$ telomeric to rs 1079635 . Evidence for linkage $(P=0.009)$ was also found at 16q23 in a second independent genomewide screen on 259 brothers from the same group [13]. A genome-wide scan on 12 hereditary prostate cancer families, each having one family member diagnosed with pancreatic cancer, also displayed some evidence for linkage at 16q23 (Kong and Cox LOD = 1.05 at D16S3098; $P=0.01$ ) [14]. D16S3098 is approximately $4 \mathrm{Mb}$ from rs 1079635 and is within the 2-LOD, but not the 1-LOD support interval of our linkage signal.

Tumor studies have demonstrated multiple regions with loss of heterozygosity on chromosome 16q that included 16q23 [15]. Paris et al. [16] reported significant LOH at D16S3096 and D16S516 (45\% and 53\%, respectively) in 51 prostate tumor samples. Although the tumors in this study were not specifically limited to men with hereditary prostate cancer, the allelic imbalance observed at markers D16S3096 and D16S516 was associated with family history of prostate cancer, suggesting the existence of a tumor suppressor gene in this region.

As previously noted, there are several candidate genes under our linkage peak, but the most obvious gene for further consideration is the tumor-suppressor gene WWOX [17]. The WWOX gene is large (>1 Mb), encodes a protein containing over 400 amino acids and overlaps with the second most common human fragile site, FRA16D [18]. LOH and reduced expression of the $W W O X$ protein are common in a number of human cancers including prostate cancer [17]. The fact that the WWOX gene is frequently inactivated in human cancers has fueled the theory that it acts as a tumor suppressor gene. In pursuing this hypothesis, several studies have shown that overexpression of WWOX inhibits growth in a variety of cell lines [18]. Aqeilan et al. [19] in a study of mice with a targeted deletion of WWOX, observed that $30 \%$ of homozygous knockouts developed spontaneous osteosarcomas and all homozygotes died before 4 weeks of age, preventing further analysis of adult tumor incidence. Seventeen percent (10/58) of heterozygotes developed a variety of tumors including lymphomas, liver, gastric and lung over the next 18 months of follow-up as compared to less than $2 \%(1 / 60)$ of the wild type mice, further supporting the notion that $W W O X$ plays a critical role in tumorigenesis. 
Although WWOX is centered within our linkage peak, additional candidate genes are within the 1-LOD support interval (Figure 2). The transcription factor ATBF1 was shown by Sun et al. [20] to contain somatic mutations in $36 \%$ of cancers and some of these mutations appear to impair function. The breast cancer antiestrogen resistance 1 (BCARI) gene expression has been shown to be inversely correlated with 16q23 LOH [21]. A panel of six genes that map to 16q23ter were shown to be consistently downregulated in prostate cancer compared to normal prostate tissue including two genes in our 1-LOD support interval: WWOX and the transcription factor $M A F$ [22].

A limited number of studies have been conducted to identify aggressive prostate cancer genes, and no such study has reported significant or suggestive evidence of linkage for aggressive prostate cancer to $9 \mathrm{q} 33$. Analysis of 188 hereditary prostate cancer families from Johns Hopkins University showed evidence for prostate cancer linkage to 9q34 (LOD = 2.17; near marker D9S1825), but this report did not focus on aggressive prostate cancer [23]. A number of studies have performed quantitative trait linkage analyses on Gleason score, a measure of prostate cancer aggressiveness. Witte et al. [13] reported modest evidence for linkage to 9q34 (LOD $=1.2, P=0.009$ near marker $D 9 S 1825)$ when analyzing Gleason score. Candidate genes on chromosome 9q include the T-cell acute lymphoblastic leukemia 2 (TAL2) gene which is altered in approximately $25 \%$ of T-cell leukemias and the deleted in bladder cancer 1 $(D B C 1)$ gene.

Previously, the PCGP conducted a whole genome linkage scan on 175 independent prostate cancer families and a subsequent analysis of aggressive prostate cancer on a subset of 71 pedigrees with two or more cases of aggressive prostate cancer [5,24]. The families participating in the first genome scan do not overlap with the families genotyped for the current analysis. The initial genome-wide scan on the first 175 PCGP families revealed suggestive linkage to $17 \mathrm{q} 21(\mathrm{LOD}=2.36)$. The subsequent analysis in a subset of 71 pedigrees with 2 or more cases of aggressive prostate cancer provided significant evidence for linkage at $15 \mathrm{q} 12$ $(\mathrm{LOD}=3.49)$ and suggestive evidence at $6 \mathrm{p} 22(\mathrm{LOD}=2.09)$ [5]. In the current study, only modest evidence for prostate cancer linkage was observed at $17 \mathrm{q} 21(\mathrm{LOD}=0.28)$ and no evidence for aggressive prostate cancer linkage was detected at $6 \mathrm{p} 22$ or 15q12 (LOD $=0.00$ at both locations). Conversely, no evidence for prostate cancer linkage was detected in the first 175 PCGP pedigrees at $16 \mathrm{q} 23(\mathrm{LOD}=0.00)$ or for aggressive prostate cancer linkage at $9 \mathrm{q} 33$ $(\mathrm{LOD}=0.07)$.

The inconsistent linkage results between the first 175 pedigrees and the current 131 PCGP pedigrees inevitably calls into question the similarity between families included in the original genome-wide scan and the new families. To address this issue, a comparison of the clinical characteristics reveal that the prostate cancer cases among families in the current scan are on average approximately 2 years younger at the time of diagnosis compared to the cases from the original families (Table I). Otherwise, the two sets of pedigrees were remarkably similar with respect to the number of cases with aggressive disease and the number of confirmed affected relatives per family.

The inconsistency of linkage results across different studies continues to plague genome-wide linkage scans of prostate cancer and has been largely attributed to not only the genetic, but also the clinical heterogeneity of the disease. One potential solution is stratified analysis, creating homogenous clinical strata according to disease aggressiveness, the influence of family history and age of diagnosis. This strategy requires large pools of affected individuals accomplished through combining participants from multiple studies, and further requires consistent clinical definition across studies and employing methods to correct findings to reduce the probability of spurious positive results due to multiple comparisons [2]. This has been one of the principal goals in the formation of the ICPCG. In this study of 131 PCGP pedigrees, we found weak 
supportive evidence for linkage to all five identified regions in the collaborative report by the ICPCG, namely: 5q12 (LOD = 0.18), 8p21 (LOD = 0.52), 15q11 (LOD = 0.35), 17q21 (LOD $=0.28)$, and 22q12 $(\mathrm{LOD}=0.28)$. Clearly, given the tremendous genetic and phenotypic heterogeneity of prostate cancer, a substantial number of additional prostate cancer families will have to be collected, analyzed and combined before any final conclusions can be drawn regarding the validity of linkage at each of these regions.

\section{CONCLUSIONS}

In summary, prostate cancer linkage studies have been used for localizing regions of the genome to target for candidate gene searches. The previous studies implicating 16q23 have all included sibships and families from the same research team [11-13]. For the first time, we have independently confirmed prostate cancer linkage to 16q23 using a set of families collected by the University of Michigan PCGP. This region has been intently studied based on the observation that deletion of $16 \mathrm{q}$ markers is commonly seen in sporadic cancers of many types including prostate cancer. Our linkage report should stimulate renewed research interest in this genomic region, and we believe that use of families with linkage evidence in combination with tumor studies should facilitate the discovery of any 16q23 tumor suppressor gene that contributes to prostate cancer susceptibility.

\section{Acknowledgments}

Grant sponsor: NIH; Grant numbers: R01 CA79596, K07 CA127214.

\section{REFERENCES}

1. Jemal A, Siegel R, Ward E, Hao Y, Xu J, Murray T, Thun MJ. Cancer statistics, 2008. CA Cancer J Clin 2008;58:71-96. [PubMed: 18287387]

2. Schaid DJ. The complex genetic epidemiology of prostate cancer. Hum Mol Genet 2004;13(Spec No 1):R103-R121. [PubMed: 14749351]

3. Witte JS. Multiple prostate cancer risk variants on 8q24. Nat Genet 2007;39:579-580. [PubMed: 17460686]

4. Xu J, Dimitrov L, Chang BL, Adams TS, Turner AR, Meyers DA, Eeles RA, Easton DF, Foulkes WD, Simard J, Giles GG, Hopper JL, Mahle L, Moller P, Bishop T, Evans C, Edwards S, Meitz J, Bullock S, Hope Q, Hsieh CL, Halpern J, Balise RN, Oakley-Girvan I, Whittemore AS, Ewing CM, Gielzak M, Isaacs SD, Walsh PC, Wiley KE, Isaacs WB, Thibodeau SN, McDonnell SK, Cunningham JM, Zarfas KE, Hebbring S, Schaid DJ, Friedrichsen DM, Deutsch K, Kolb S, Badzioch M, Jarvik GP, Janer M, Hood L, Ostrander EA, Stanford JL, Lange EM, Beebe-Dimmer JL, Mohai CE, Cooney KA, Ikonen T, Baffoe-Bonnie A, Fredriksson H, Matikainen MP, Tammela TLJ, Bailey-Wilson J, Schleutker J, Maier C, Herkommer K, Hoegel JJ, Vogel W, Paiss T, Wiklund F, Emanuelsson M, Stenman E, Jonsson BA, Gronberg H, Camp NJ, Farnham J, Cannon-Albright LA, Seminara D. A combined genomewide linkage scan of 1,233 families for prostate cancer susceptibility genes conducted by the international consortium for prostate cancer genetics. Am J Hum Genet 2005;77:219229. [PubMed: 15988677]

5. Lange EM, Ho LA, Beebe-Dimmer JL, Wang Y, Gillanders EM, Trent JM, Lange LA, Wood DP, Cooney KA. Genome-wide linkage scan for prostate cancer susceptibility genes in men with aggressive disease: Significant evidence for linkage at chromosome 15q12. Hum Genet 2006;119:400-407. [PubMed: 16508751]

6. Schaid DJ. Pooled genome linkage scan of aggressive prostate cancer: Results from the International Consortium for Prostate Cancer Genetics. Hum Genet 2006;120:471-485. [PubMed: 16932970]

7. Abecasis GR, Cherny SS, Cookson WO, Cardon LR. Merlin-rapid analysis of dense genetic maps using sparse gene flow trees. Nat Genet 2002;30:97-101. [PubMed: 11731797]

8. Whittemore AS, Halpern J. A class of tests for linkage using affected pedigree members. Biometrics 1994;50:118-127. [PubMed: 8086596] 
9. Kong A, Cox NJ. Allele-sharing models: LOD scores and accurate linkage tests. Am J Hum Genet 1997;61:1179-1188. [PubMed: 9345087]

10. Lander E, Kruglyak L. Genetic dissection of complex traits: Guidelines for interpreting and reporting linkage results. Nat Genet 1995;11:241-247. [PubMed: 7581446]

11. Suarez BK, Lin J, Burmester JK, Broman KW, Weber JL, Banerjee TK, Goddard KA, Witte JS, Elston RC, Catalona WJ. A genome screen of multiplex sibships with prostate cancer. Am J Hum Genet 2000;66:933-944. [PubMed: 10712208]

12. Suarez BK, Lin J, Witte JS, Conti DV, Resnick MI, Klein EA, Burmester JK, Vaske DA, Banerjee TK, Catalona WJ. Replication linkage study for prostate cancer susceptibility genes. Prostate 2000;45:106-114. [PubMed: 11027409]

13. Witte JS, Suarez BK, Thiel B, Lin J, Yu A, Banerjee TK, Burmester JK, Casey G, Catalona WJ. Genome-wide scan of brothers: Replication and fine mapping of prostate cancer susceptibility and aggressiveness loci. Prostate 2003;57:298-308. [PubMed: 14601026]

14. Pierce BL, Friedrichsen-Karyadi DM, McIntosh L, Deutsch K, Hood L, Ostrander EA, Austin MA, Stanford JL. Genomic scan of 12 hereditary prostate cancer families having an occurrence of pancreas cancer. Prostate 2007;67:410-415. [PubMed: 17192958]

15. Saramaki O, Visakorpi T. Chromosomal aberrations in prostate cancer. Front Biosci 2007;12:32873301. [PubMed: 17485299]

16. Paris PL, Witte JS, Kupelian PA, Levin H, Klein EA, Catalona WJ, Casey G. Identification and fine mapping of a region showing a high frequency of allelic imbalance on chromosome 16q23.2 that corresponds to a prostate cancer susceptibility locus. Cancer Res 2000;60:3645-3649. [PubMed: 10910080]

17. Qin HR, Iliopoulos D, Semba S, Fabbri M, Druck T, Volinia S, Croce CM, Morrison CD, Klein RD, Huebner K. A role for the WWOX gene in prostate cancer. Cancer Res 2006;66:6477-6481. [PubMed: 16818616]

18. Aqeilan RI, Croce CM. WWOX in biological control and tumorigenesis. J Cell Physiol 2007;212:307310. [PubMed: 17458891]

19. Aqeilan RI, Trapasso F, Hussain S, Costinean S, Marshall D, Pekarsky Y, Hagan JP, Zanesi N, Kaou M, Stein GS, Lian JB, Croce CM. Targeted deletion of Wwox reveals a tumor suppressor function. Proc Natl Acad Sci USA 2007;104:3949-3954. [PubMed: 17360458]

20. Sun X, Frierson HF, Chen C, Li C, Ran Q, Otto KB, Cantarel BL, Vessella RL, Gao AC, Petros J, Miura Y, Simons JW, Dong JT. Frequent somatic mutations of the transcription factor ATBF1 in human prostate cancer. Nat Genet 2005;37:407-412. [PubMed: 15750593]

21. Fromont G, Vallancien G, Validire P, Levillain P, Cussenot O. BCAR1 expression in prostate cancer: Association with 16q23 LOH status, tumor progression and EGFR/KAI1 staining. Prostate 2007;67:268-273. [PubMed: 17192874]

22. Watson JE, Doggett NA, Albertson DG, Andaya A, Chinnaiyan A, van DH, Ginzinger D, Haqq C, James K, Kamkar S, Kowbel D, Pinkel D, Schmitt L, Simko JP, Volik S, Weinberg VK, Paris PL, Collins C. Integration of high-resolution array comparative genomic hybridization analysis of chromosome $16 \mathrm{q}$ with expression array data refines common regions of loss at 16q23-qter and identifies underlying candidate tumor suppressor genes in prostate cancer. Oncogene 2004;23:34873494. [PubMed: 15007382]

23. Xu J, Gillanders EM, Isaacs SD, Chang BL, Wiley KE, Zheng SL, Jones MP, Gildea D, Reidesel E, Albertus J, Freas-Lutz D, Markey C, Meyers DA, Walsh PC, Trent JM, Isaacs WB. Genome-wide scan for prostate cancer susceptibility genes in the John Hopkins hereditary prostate cancer families. Prostate 2003;57:320-325. [PubMed: 14601028]

24. Lange EM, Gillanders EM, Davis CC, Brown WM, Campbell JK, Jones MP, Gildea D, Riedesel E, Albertus J, Freas-Lutz D, Markey C, Giri V, Beebe-Dimmer J, Montie JE, Trent JM, Cooney KA. Genome-wide scan for prostate cancer susceptibility genes using families from the University of Michigan Prostate Cancer Genetics Project finds evidence for linkage on chromosome 17 near BRCA1. Prostate 2003;57:326-334. [PubMed: 14601029] 

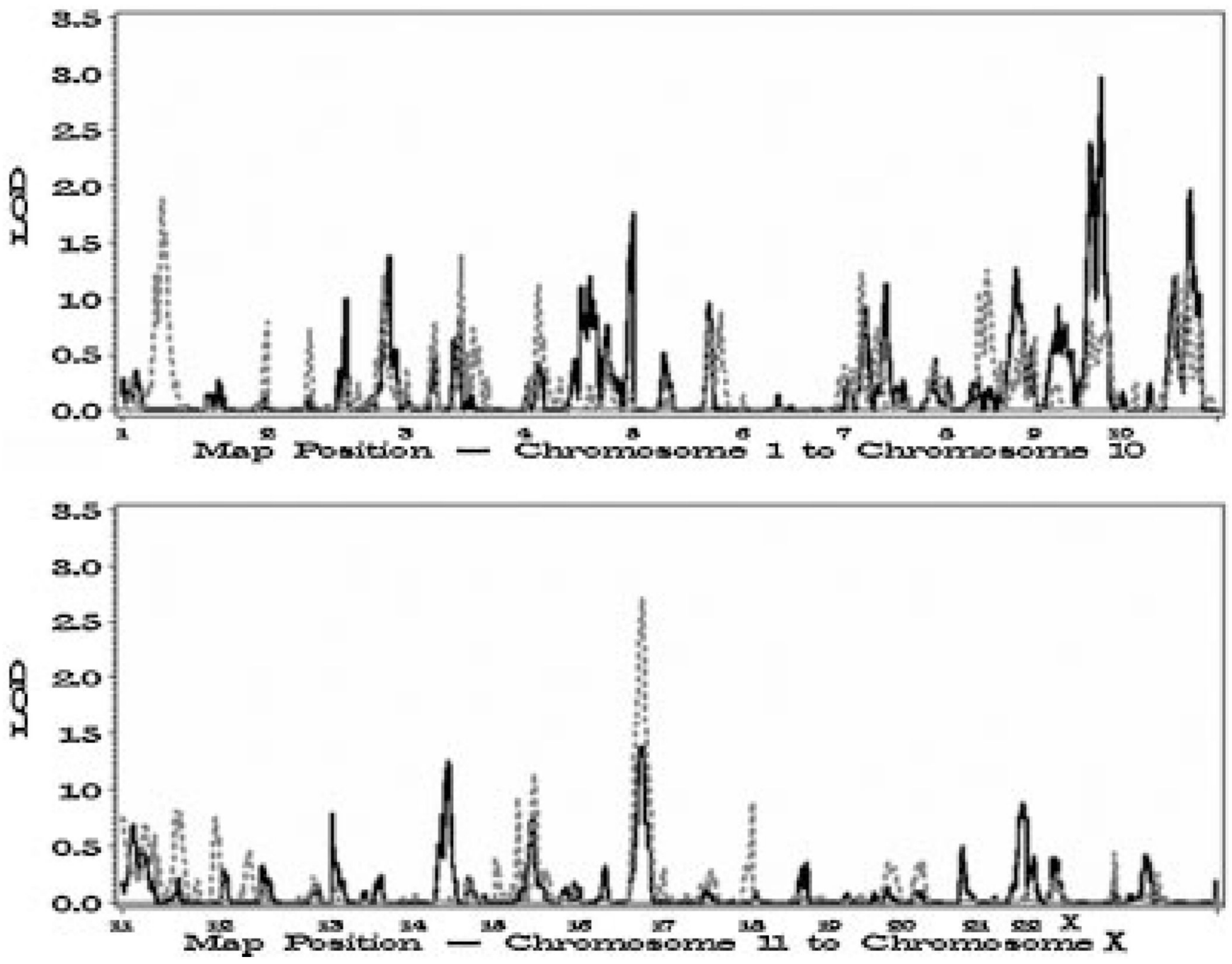

Fig. 1.

Genome-wide linkage results for prostate cancer from 131 PCGP families (gray dashed line) and aggressive prostate cancer from 57 PCGP families with two or more cases of aggressive prostate cancer (solid black line). 


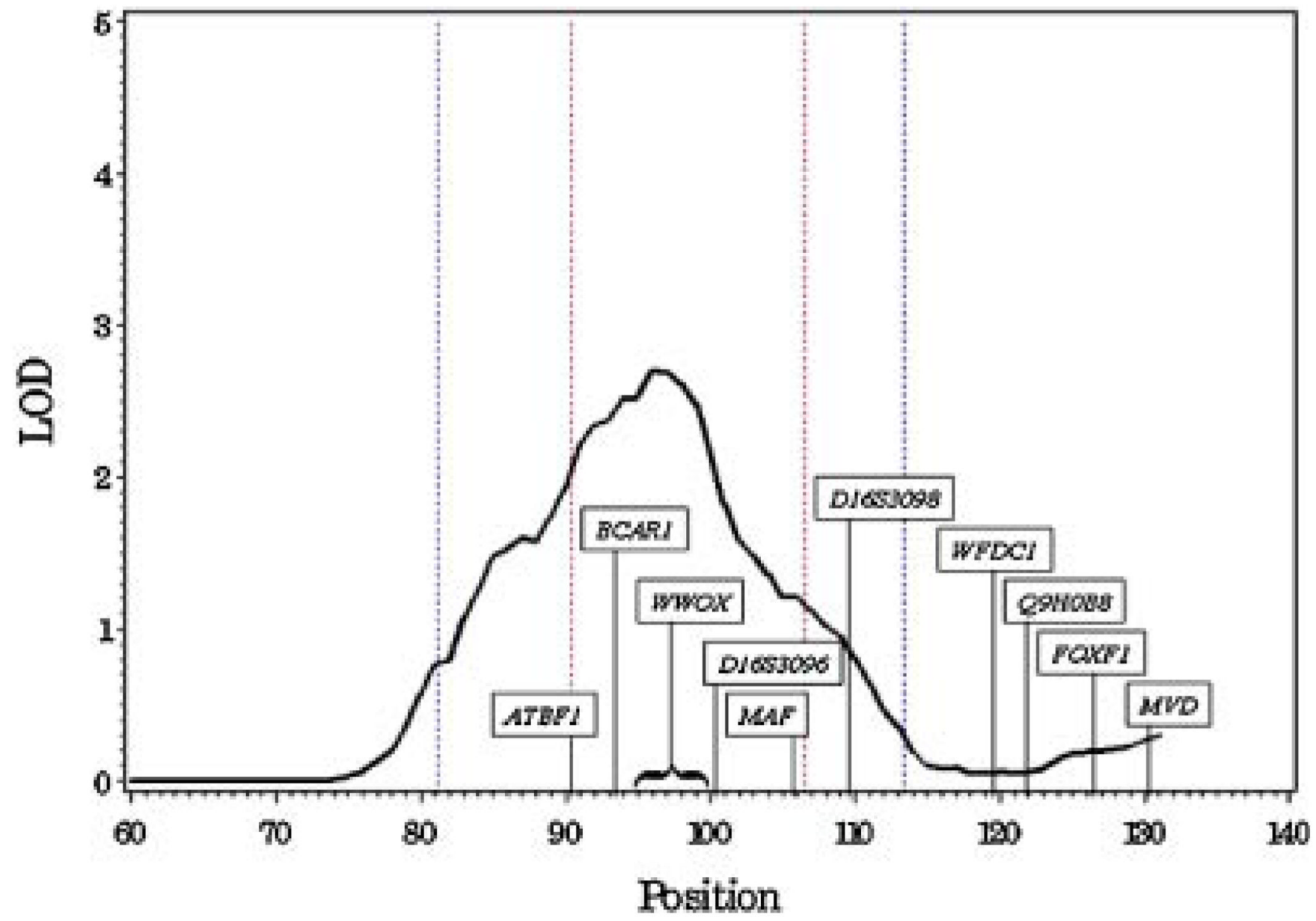

Fig. 2.

Linkage results for all 131 families at 16q.The1-LOD support interval (redlines) is defined by markers rs71953 andrs1125733. Candidate genes ATBF1, BCAR1,WWOX, and MAF, as well as the microsatellite marker D16S3096, are each within the 1-LOD support interval. The 2LOD support interval is defined by markers rs716455 and rs7190151, and microsatellite marker D16S3098 is within the 2-LOD but not the 1-LOD support interval. The six genes that were reported by Watson et al. [22] to show reduced expression in prostate cancer compared to normal prostate tissue using quantitative expression analysis are:WWOX,WFDC1, MAF, $F O X F 1, M V D$ and predicted transcript $Q 9 H 0 B 8$. 
TABLE I

A Comparison of Characteristics Between PCGP Families Included in the First and Second Genome Wide Linkage Scans (GWS)

\begin{tabular}{lccc}
\hline & First GWS & $\begin{array}{c}\text { First GWS } \\
\text { (Caucasian families) }\end{array}$ & Second GWS \\
\hline $\begin{array}{l}\text { No. of families } \\
\begin{array}{l}\text { Mean age at diagnosis (SD) among affected } \\
\text { relatives }\end{array}\end{array}$ & 175 & 157 & 131 \\
$\%$ of families with average age of diagnosis & 64 years (5.7 years) \\
$\leq 65$ years & $61 \%$ & $61 \%$ & 62 years (6.3 years) \\
$\begin{array}{l}\text { Mean number of confirmed affected relatives } \\
\text { (SD) }\end{array}$ & $3.9(1.8)$ & $3.8(1.5)$ & $72 \%$ \\
$\begin{array}{l}\% \text { of families with four or more affected } \\
\text { relatives } \\
\% \text { of cases characterized as having aggressive } \\
\text { disease } a\end{array}$ & $45 \%$ & $43 \%$ & 4.8 (1.4) \\
\hline
\end{tabular}

$\mathrm{SD}$, standard deviation.

${ }^{a}$ Aggressive disease defined as having T stage 3 and higher or N1 or M1 or Gleason grade of $\geq 7$, or pre-diagnostic PSA of $>20 \mathrm{ng} / \mathrm{ml}$ or prostate cancer listed as primary cause of death on the death certificate. 


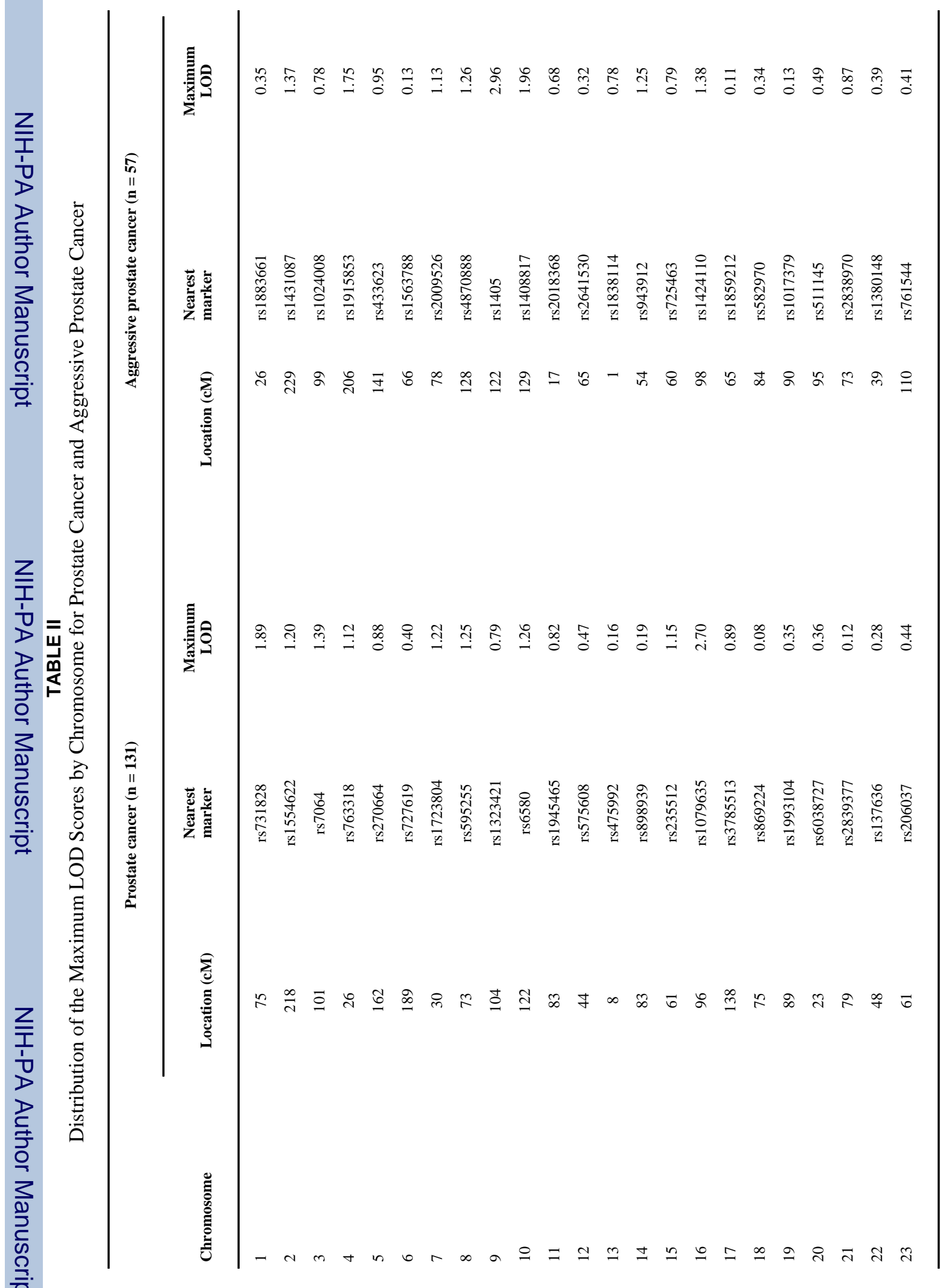

훔 